\title{
LRRK2 kinase inhibition prevents pathological microglial phagocytosis in response to HIV-1 Tat protein
}

Daniel F Marker ${ }^{\dagger}$, Jenna M Puccini ${ }^{*}$, Taryn E Mockus, Justin Barbieri, Shao-Ming Lu and Harris A Gelbard

\begin{abstract}
Background: Human Immunodeficiency Virus-1 (HIV-1) associated neurocognitive disorders (HANDs) are accompanied by significant morbidity, which persists despite the use of combined antiretroviral therapy (CART). While activated microglia play a role in pathogenesis, changes in their immune effector functions, including phagocytosis and proinflammatory signaling pathways, are not well understood. We have identified leucine-rich repeat kinase 2 (LRRK2) as a novel regulator of microglial phagocytosis and activation in an in vitro model of HANDs, and hypothesize that LRRK2 kinase inhibition will attenuate microglial activation during HANDs.

Methods: We treated BV-2 immortalized mouse microglia cells with the HIV-1 trans activator of transcription (Tat) protein in the absence or presence of LRRK2 kinase inhibitor (LRRK2i). We used Western blot, qRT-PCR, immunocytochemistry and latex bead engulfment assays to analyze LRRK2 protein levels, proinflammatory cytokine and phagocytosis receptor expression, LRRK2 cellular distribution and phagocytosis, respectively. Finally, we utilized ex vivo microfluidic chambers containing primary hippocampal neurons and BV-2 microglia cells to investigate microglial phagocytosis of neuronal axons.
\end{abstract}

Results: We found that Tat-treatment of BV-2 cells induced kinase activity associated phosphorylation of serine 935 on LRRK2 and caused the formation of cytoplasmic LRRK2 inclusions. LRRK2i decreased Tat-induced phosphorylation of serine 935 on LRRK2 and inhibited the formation of Tat-induced cytoplasmic LRRK2 inclusions. LRRK2i also decreased Tat-induced process extension in BV-2 cells. Furthermore, LRRK2i attenuated Tat-induced cytokine expression and latex bead engulfment. We examined relevant cellular targets in microfluidic chambers and found that Tat-treated BV-2 microglia cells cleared axonal arbor and engulfed neuronal elements, whereas saline treated controls did not. LRRK2i was found to protect axons in the presence of Tat-activated microglia, as well as AnnexinV, a phosphatidylserine-binding protein. In addition, LRRK2i decreased brain-specific angiogenesis inhibitor 1 (BAl1) receptor expression on BV-2 cells after Tat-treatment, a key receptor in phosphatidylserine-mediated phagocytosis.

Conclusion: Taken together, these results implicate LRRK2 as a key player in microglial inflammation and, in particular, in the phagocytosis of neuronal elements. These studies show that LRRK2 kinase inhibition may prove an effective therapeutic strategy for HANDs, as well as other neuroinflammatory conditions.

Keywords: Phagocytosis, Microglia, HIV-1, Tat, Leucine-rich repeat kinase 2 (LRRK2), AnnexinV, Parkinson's disease, Brain-specific angiogenesis inhibitor 1 (BAl1)

\footnotetext{
* Correspondence: Jenna_Puccini@urmc.rochester.edu

${ }^{\dagger}$ Equal contributors

Center for Neural Development and Disease, Department of Neurology,

Child Neurology Division, University of Rochester, Rochester, NY, USA
} 


\section{Background}

Human Immunodeficiency Virus-1 (HIV-1) associated neurocognitive disorders (HANDs) are a serious and growing cause of disability despite the use of combination antiretroviral therapy (cART) [1]. HIV-1 invades the central nervous system (CNS) early after infection and targets invading peripheral macrophage and resident microglia, which serve as a viral reservoir [2,3]. While cART suppresses viral replication throughout the host, early viral proteins are still produced in the CNS due to the presence of integrated proviral DNA [4]. In particular, the HIV-1 trans activator of transcription (Tat) protein is produced within the CNS despite administration of cART $[5,6]$. The HIV-1 Tat protein has been found to mediate damage in the CNS by upregulating chemotactic gradients that favor monocyte recruitment with accompanying neurotoxicity [7]. Furthermore, a single dose of Tat in the murine CNS can provide a model for the neuroinflammation, persistent synaptic damage and neurodegeneration associated with HANDs [8].

Leucine-rich repeat kinase 2 (LRRK2) is a $286 \mathrm{kDa}$ signaling protein that has many domains, including a GTPase, a mitogen-activated protein kinase kinase kinase (MAPKKK) and a WD-40 domain [9]. Several of the LRRK2 domains are phosphorylated through both autophosphorylation and constitutive phosphorylation [10]. In particular, phosphorylation of serine 935 (pS935) has been linked to kinase activity in LRRK2 [11], where LRRK2 kinase inhibition has been shown to decrease pS935 in HEK 293 cells [12]. The commercially available LRRK2 kinase inhibitor used in this study is highly specific for LRRK2, as it was found to inhibit only 12 out of 442 kinases based on kinase-binding and biochemical assays [12].

Mutations in LRRK2 have been found to modify susceptibility to several diseases with inflammatory components, including Parkinson's disease (PD), Crohn's disease (CD) and leprosy [13-15]. LRRK2 is highly expressed in immune cells, including monocytes, B-cells and T-cells, and this expression has been shown to increase after both lipopolysaccharide (LPS) and lentiviral particle treatment in macrophages [16]. Paradoxically, LRRK2 deficiency exacerbates experimentally induced colitis in mice [17], suggesting a phenotypic role for LRRK2 in CD. Conversely, LRRK2 knockout microglia exhibit attenuated microglial inflammation after LPS exposure, in which microglial activation has been implicated in modulating PD $[18,19]$. Moreover, LRRK2 has been found to increase nuclear factor-kappa beta (NF$\kappa \beta)$ activity in both CD and PD models [20,21]. Thus, LRRK2 plays an important role in inflammation that may have opposing effects based on the unique microenvironment and signaling pathways associated with the given disorder [22].
LRRK2 is a compelling target in understanding neurodegeneration, as mutations in LRRK2 are the most common single gene cause of PD and are found in both familial and sporadic cases of disease [23,24]. PD is a neurodegenerative disorder that is characterized by a loss of dopaminergic neurons in the substantia nigra (SN). The PD-associated mutation LRRK2(G2019S), which causes an increase in LRRK2 kinase activity, has been shown to cause dendritic degeneration and dopaminergic neuronal loss in LRRK2(G2019S) transgenic mice [25]. These animals also exhibited impaired adult neurogenesis and neurite outgrowth [26]. However, LRRK2 is not strongly expressed in the SN [27] and LRRK2 knockout mice were found to have abnormalities in protein processing in the kidneys and not in the brain [28]. Therefore, recent studies have focused on the role of LRRK2 in microglial inflammation, as the $\mathrm{SN}$ has the highest density of microglia in the CNS [29].

Recent studies have implicated LRRK2 in neuroinflammation and microglial inflammatory responses [18,21,30]. The PD-associated mutation, LRRK2(R1441G), which also alters LRRK2 kinase activity, has been shown to increase pro-inflammatory cytokine release in microglia, which was found to induce neurotoxicity [30]. Another publication by Moehle et al. has implicated LRRK2 in microglial inflammatory responses after exposure to LPS [18]. These results included inhibition of LPS-induced tumor necrosis factor- $\alpha$ $(\mathrm{TNF}-\alpha)$ release, chemotaxis and microglial process extension after LRRK2 knockdown. A similar study by Kim et al. indicated that LRRK2 regulates LPS-induced microglial activation by altering NF- $\kappa \beta$, p38 and Jun N-terminal kinase (JNK) signaling [21].

As the pathogenicity of LRRK2 activation in microglia during HANDs remains unexplored, and given the neuropathogenic overlaps between HANDs and PD, we investigated the role of LRRK2 in a novel in vitro model of HANDs. Phagocytic engulfment has not been studied in relation to LRRK2, even though LRRK2 has been linked to Rac-1, a small Rho GTPase that plays a role in actin remodeling during phagocytosis [31]. Furthermore, the use of microfluidic chambers utilizes a highly novel and physiologically relevant technique to study this phenomenon. As the effects of Tat have been shown to be reversible [32], preventing pro-inflammatory cytokine release and increased phagocytosis during HANDs may be neuroprotective. This has led us to hypothesize that HIV-1 Tat increases microglial production of proinflammatory cytokines and phagocytosis of synaptic elements in a LRRK2-dependent manner.

\section{Methods}

\section{Cell lines and reagents}

We maintained the BV-2 mouse microglia cell line (kind gift of Dr. Sanjay B. Maggirwar) in 10\% fetal bovine 
serum (FBS) (Atlas, Fort Collins, CO, USA, F-0500-A) in (D)MEM (Cellgro, Manassas, VA, USA 15-013-CV) with 2 mM GlutaMax (Gibco, Grand Island, NY, USA, 35050061) and penicillin-streptomycin (Gibco, 15140-122) at $37^{\circ} \mathrm{C}$ at $5 \% \mathrm{CO}_{2}$. We dissected 18-day embryonic rat pups to obtain hippocampal neurons for our microfluidic coculture experiments. We plated and maintained primary hippocampal neurons in Neurobasal media (Gibco, 21103-049) supplemented with 5\% FBS, B27 supplement (Gibco, 17504-044), $2 \mathrm{mM}$ GlutaMax, and 50uM Lglutamic acid (Sigma, St. Louis, MO, USA, G5889100G). We resuspended and plated BV-2 cells in the same supplemented Neurobasal media for all co-culture experiments. We obtained full length HIV-1 Tat ${ }_{101}$ from Philip Ray (University of Kentucky) that we used for all experiments involving Tat exposure. We purchased the small molecule LRRK2 kinase inhibitor LRRK2-IN-1 (LRRK2i) from Millipore (Billerica, MA, USA, 438193, 1 $\mu \mathrm{M}$ working concentration) and purified AnnexinV from eBioscience (San Diego, CA, USA BMS306, working concentration $1 \mu \mathrm{g} / \mathrm{ml})$. Unless otherwise noted, we plated BV-2 cells in poly-D-lysine (Sigma, P1149-100 mg) coated 12-well plates or on glass coverslips without penicillin-streptomycin overnight and treated as indicated with $1 \mu \mathrm{g} / \mathrm{ml} \mathrm{Tat}_{101}$, saline vehicle control, dimethyl sulfoxide (DMSO) vehicle control, or $1 \mu \mathrm{M}$ LRRK2i for 12 hours, as indicated by our preliminary time-course experiments (data not shown). For BV-2 cell counts, we used a hemocytometer with 0.4\% trypan blue stain (Gibco, 15250).

\section{Western blotting}

We harvested cells by scraping into $1 \mathrm{X}$ PBS and centrifuging at 7,000 rpm for 1 minute. We resuspended the pellet in cell lysis buffer with protease inhibitors and lysed it on ice with periodic vortexing for 30 minutes. We normalized protein concentration by Bradford assay (BioRad, Hercules, CA, USA 500-0113, 500-0114, 500-0115). We mixed $10 \mu \mathrm{g}$ of sample with loading dye, heated it at $70^{\circ} \mathrm{C}$ for 5 minutes, and ran it on a $4 \%$ to $15 \%$ SDS-PAGE gel (BioRad, 456-1086) at $100 \mathrm{~V}$ for 1 hour. We transferred the gel onto a polyvinylidene difluoride (PVDF) membrane at $100 \mathrm{~V}$ for 1 hour on ice. We blocked membranes in 5\% milk in 1X Tris-buffered saline (TBS) for 1 hour at room temperature with shaking. We washed membranes 3 times in $1 \mathrm{X}$ Tris-buffered saline with $0.1 \%$ Triton-X 100 (TBST) . We applied primary antibodies overnight at $4{ }^{\circ} \mathrm{C}$ with shaking in 5\% milk in $1 \mathrm{X}$ TBST at the following concentrations; rabbit anti-LRRK2 (1:1000) (Epitomics, Burlingame, CA, USA, 3514-1), rabbit anti-pS935-LRRK2 (1:1000) (Epitomics, 5099-1), $\beta$-actin (1:500) (Santa Cruz, Santa Cruz, CA, USA, sc-47778) . We washed membranes 3 times in 1X TBST. We applied horseradish peroxidase (HRP)-conjugated secondary antibody (GE Healthcare,
Pittsburgh, PA, USA ) at a concentration of 1:5,000 in 5\% milk in $1 \mathrm{X}$ TBST for 1 hour at room temperature with shaking. We washed membranes and applied enhanced chemiluminescence (ECL) substrate (Pierce, Rockford, IL, USA, 32106) for 1 minute. We exposed and developed membranes on film (Kodak, Rochester, NY, USA, 111-1681).

\section{qRT-PCR}

We isolated RNA from BV-2 cells using the RNeasy RNA isolation kit (Qiagen, Valencia, CA, USA, 74104). We synthesized cDNA from $0.5 \mu \mathrm{g}$ of total RNA using the SuperScript III First-Strand Synthesis System (Invitrogen, Carlsbad, CA, USA, 18080-051). We used the TaqMan Universal PCR Master Mix (Invitrogen, 4304437) with Invitrogen TaqMan Gene Expression Assay primers and probed for TNF- $\alpha$ (Mm00443258_m1), IL-6 (Mm00446190_m1), MCP-1 (Mm00441242_m1), IL-10 (Mm00439614_m1), IL-4 (Mm00445259_m1), BAI1 (Mm01195143_m1), Tim4 (Mm00724709_m1) and 18S ribosomal RNA (Mm03928990_g1) as an internal control. We ran and measured the samples on an Applied Biosystems (Carlsbad, CA, USA) StepOnePlus real time PCR machine. We analyzed relative target gene levels by comparing the fold change of delta-delta threshold cycle to the control after normalization to $18 \mathrm{~S}$ ribosomal RNA.

\section{Immunocytochemistry}

We adapted our immunocytochemistry (ICC) protocol from Glynn et al. [33]. Briefly, we fixed the cells in a solution of $4 \%$ paraformaldehyde, $4 \%$ sucrose in $1 \mathrm{x}$ PBS at $4 \mathrm{C}$ for 10 minutes. We then treated the fixed cells with $100 \mathrm{mM}$ glycine in $1 \mathrm{x}$ PBS and washed in 1x PBS for 5 minutes. We prepared the primary antibodies in 3\% BSA (Sigma, A3294-50 G) in 1x PBS at the following concentrations: rat anti CD11b 1:200 (Serotech, MCA711), mouse anti Tau5 1:500 (Calbiochem, 577801), rabbit anti Synapsin-1 1:500 (Cell Signaling, 5297S), and rabbit anti LRRK2 1:500 (Novus, St. Charles, MO, USA, NB300-268). We incubated in the fixed cells in the primary antibody solution for 1 hour, then washed 4 times with $3 \%$ BSA, 1x PBS for five minutes apiece. We prepared alexa fluor secondary antibodies (Molecular Probes, Eugene, OR, USA) in 3\% BSA, 1x PBS at 1:500, and incubated the cells in secondary antibody for 30 minutes. We then washed the cells 4 times in $1 \mathrm{x}$ PBS for five minutes apiece, before mounting them on glass slides using the Prolong Gold with 4',6-diamidino-2-phenylindole (DAPI) mounting agent (Life Technologies, Carlsbad, CA, USA, P36935).

\section{Latex bead-based phagocytosis assays}

We exposed experimentally-treated BV-2 cells to $0.8 \mu \mathrm{m}$ average diameter deep blue dyed uncharged latex beads 
(Sigma, L1398) for 1.5 hours, after which we washed, scraped, and sonicated the cell/bead suspension. We measured the absorbance of the resulting solution on a visible light spectrophotometer at $595 \mathrm{~nm}$ to obtain a quantitative readout for bead phagocytosis. We also exposed BV-2 cells experimentally treated as indicated for 6 hours with $1 \mu \mathrm{m}$ average diameter fluorescent, carboxylated latex beads (Invitrogen, F8816) for 45 minutes. We washed and fixed the cells as in our ICC protocol to obtain a qualitative readout.

\section{Microfluidic chamber system}

We fabricated photoresist molds and polydimethylsiloxane (PDMS) microfluidic chambers as described by Park et al. [34]. We plasma-cleaned $22 \mathrm{~mm}$ square \#1.5 coverglass (Corning, Tewksbury, MA, USA, 2870-22) and submerged it in $50 \mu \mathrm{g} / \mathrm{ml}$ poly-d-lysine at $37^{\circ} \mathrm{C}$ overnight. We thoroughly washed and dried the glass and assembled the chambers by placing the molded PDMS on top of the glass and allowing it to seal. We then filled the chamber with media in the order described by Park. After removing the media, we added $20 \mu \mathrm{l}$ of a $3.5 \times 10^{6}$ hippocampal cells $/ \mathrm{ml}$ cell suspension to the upper left well of the chamber. We allowed the cells to attach for 15 minutes, and then filled the chamber with media as described by Park. We observed axons crossing the $400 \mu \mathrm{m}$ barrier by 3 days in vitro (DIV), with extensive neuritic networks forming by 7 DIV.

All of the chambers we used for the microfluidic experiments were 7 DIV. We imaged the chambers before treatment to obtain baseline axonal images and measurements. We then plated the experimentally treated BV-2 cells in the axon compartment by carefully removing the media from the axon wells and adding $20 \mu \mathrm{l}$ of a $3 \times 10^{6} \mathrm{BV}-2$ cells $/ \mathrm{ml}$ cell suspension to one of the axon compartment wells. We allowed the cells to attach and then filled the chamber with media. We utilized a media pressure gradient to assure that none of the soluble experimental manipulations diffused to the cell body compartment. We cultured the chambers for a further 14 hours and then obtained post treatment brightfield images. We then deconstructed the chambers and fixed the cells with $4 \%$ paraformaldehyde (Sigma, 441244), 4\% sucrose (EM Science, Gibbstown, NJ, USA, $8510)$ in $1 x$ PBS for future immunocytochemistry. Based on pilot experiments with MAP-2 and Tau5 (see below), by 7 DIV, no MAP-2 positive processes were identified that traversed the entire $400 \mu \mathrm{m}$ barrier (data not shown), suggesting that only axonal processes and growth cones were present in compartment 2.

\section{Imaging and analysis}

For our fluorescent fixed cell ICC, we imaged slides on an Olympus BX-51 upright microscope equipped with
Qioptic Optigrid optical sectioning hardware (Princeton, NJ, USA). We imaged the fixed cells with a 40x $0.8 \mathrm{NA}$ air objective with a $0.2 \mathrm{um} z$-step or using a $20 \mathrm{x} 0.58 \mathrm{NA}$ air objective with a $0.5 \mathrm{um}$ z-step. We captured images using a Hamamatsu ORCA-ER camera controlled by Perkin Elmer Volocity software, and created the representative images of the three-dimensional stacks using a z-projection in the same software. For our live cell bright-field images, we imaged the microfluidic chambers on an Olympus IX70 inverted microscope under 10x

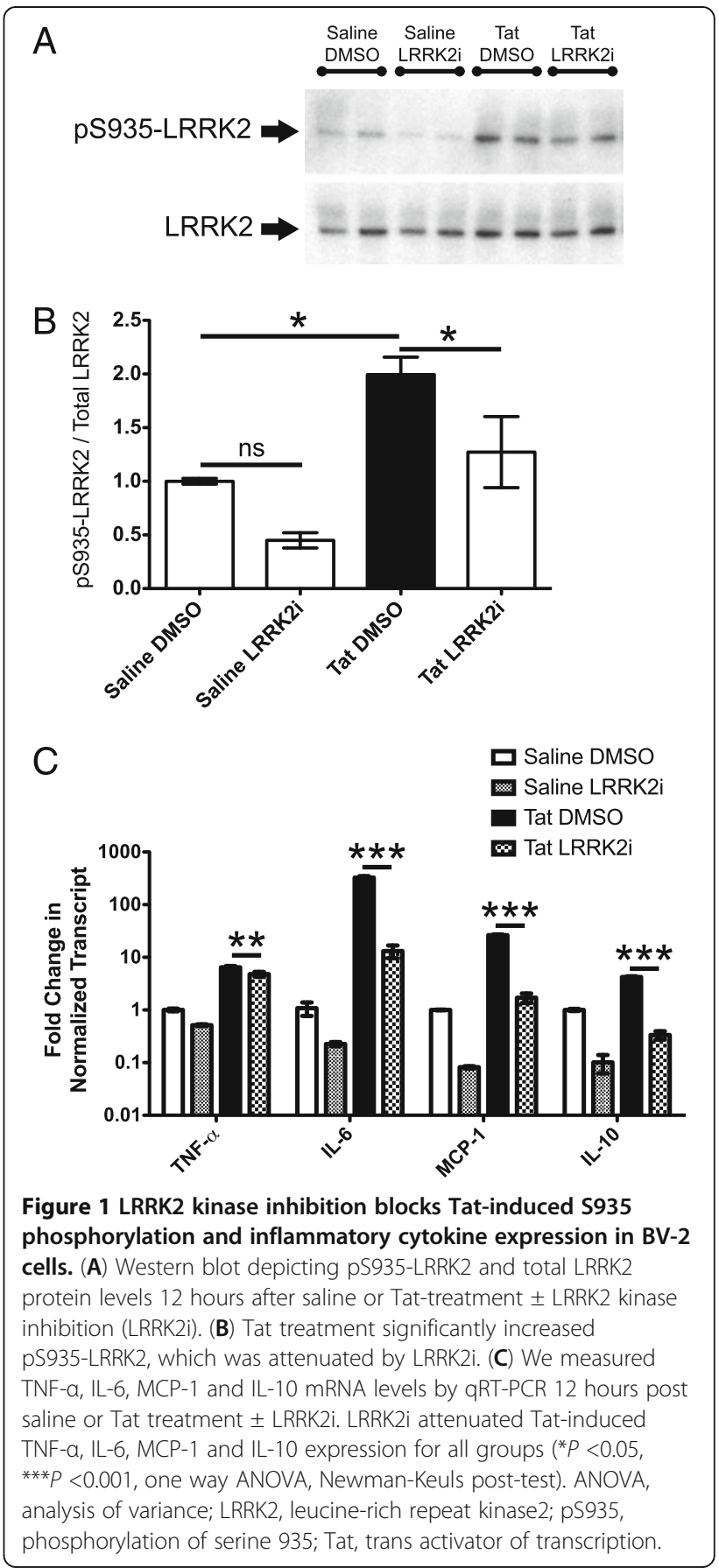


magnification. We captured the images using a PCO.edge camera controlled by the NIH image capturing software Micromanager [35]. We processed the images using $\mathrm{NIH}$ ImageJ [36] image analysis software, with the addition of the NeuronJ Java plugin for axon length analysis (www. imagescience.org/meijering/software/neuronj/) [37].

\section{Results}

\section{LRRK2 expression in BV-2 microglia cells}

In order to study LRRK2 activity in microglia, we utilized the BV-2 mouse microglia cell line. BV-2 microglia cells are biochemically similar to microglial cells found in the murine CNS and grow robustly in culture [38]. We found that Tat-treatment of BV-2 cells induced the kinase activity associated pS935 on LRRK2, which was decreased by inhibition of LRRK2i (Figure 1A, B).

\section{LRRK2 kinase inhibition attenuates Tat-induced microglial cytokine expression}

To examine microglial activation in response to HIV-1 Tat protein, we analyzed proinflammatory cytokine expression through qRT-PCR. TNF- $\alpha$, IL-6 and MCP-1, also known as CCL2, were significantly increased after Tat treatment and attenuated through LRRK2i (Figure 1C). Tat treatment did not induce IL-4 expression in BV-2 cells (data not shown). These particular cytokines were analyzed due to their increased expression in the CNS during HANDs and contribution to neurotoxicity $[39,40]$. Additionally, MCP-1 is a potent inducer of peripheral monocyte infiltration into the CNS during neuroinflammation, and also causes migration of resident microglia $[41,42]$.

\section{Altered LRRK2 cytoplasmic distribution and microglial process length after HIV-1 Tat exposure}

We then examined the effect of Tat and LRRK2i on LRRK2 distribution within BV-2 cells and on BV-2 cell morphology. ICC against LRRK2 revealed diffuse staining throughout the cytoplasm in saline control cells (Figure 2A). When the BV-2 cells are exposed to Tat, LRRK2 expression appears to be concentrated in small $1 \mu \mathrm{m}$ inclusions found throughout the cytoplasm

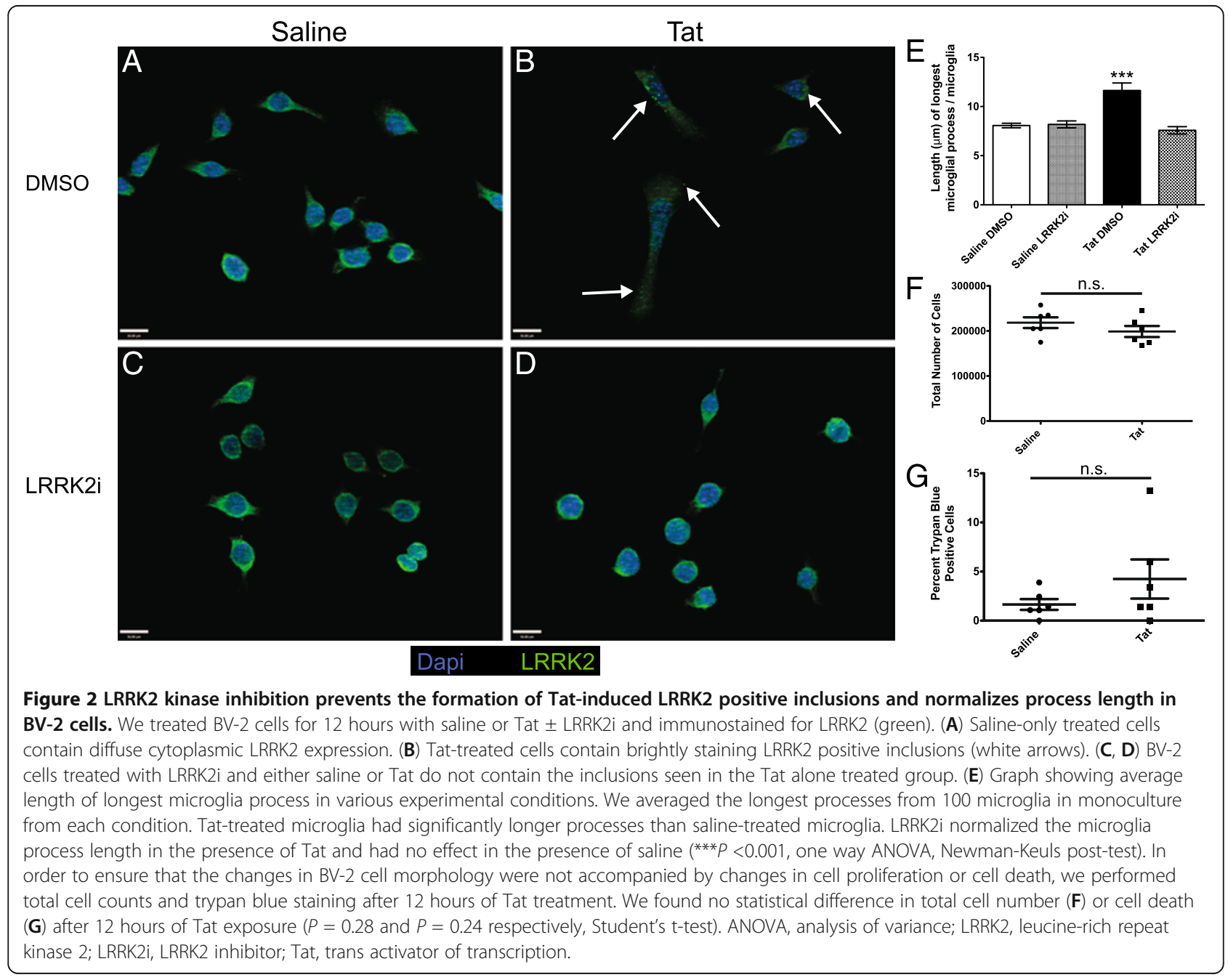


(Figure 2B). The addition of LRRK2i to the saline treated condition had no effect on LRRK2 distribution (Figure 2C), while cytoplasmic inclusions were no longer observed in the Tat-treated condition after the addition of LRRK2i (Figure 2D). BV-2 cells morphologically responded to Tat exposure by extending processes (Figure 2B), as compared to their normal amoeboid morphology (Figure 2A). While Tat increased microglia process length, LRRK2i significantly decreased process length to that of saline controls (Figure 2D, E). These results expand on previously published data showing that LRRK2i attenuates LPS-induced microglia process extension [18]. Furthermore, BV-2 cell counts indicated that Tat-treatment did not significantly alter proliferation (Figure 2F) or cell death (Figure 2G) over the experimental time course.
Tat-induced microglial phagocytosis of uncharged and carboxylated latex beads is reduced by LRRK2 kinase inhibition

In order to ascertain phagocytic capacity within Tattreated BV-2 cells, we utilized both uncharged and carboxylated latex bead engulfment assays. We found that Tat treatment significantly increased phagocytosis of uncharged, blue dyed latex beads by BV-2 cells, as compared to saline treated controls using a quantitative read-out (Figure 3A). Co-treatment with LRRK2i decreased Tat-induced phagocytosis of uncharged latex beads and also decreased basal levels of phagocytosis in saline controls treated with LRRK2i (Figure 3A). We also exposed BV-2 cells to fluorescent, carboxylated beads, in which the negative charge on the bead mimics phosphatidylserine exposure on apoptotic cells
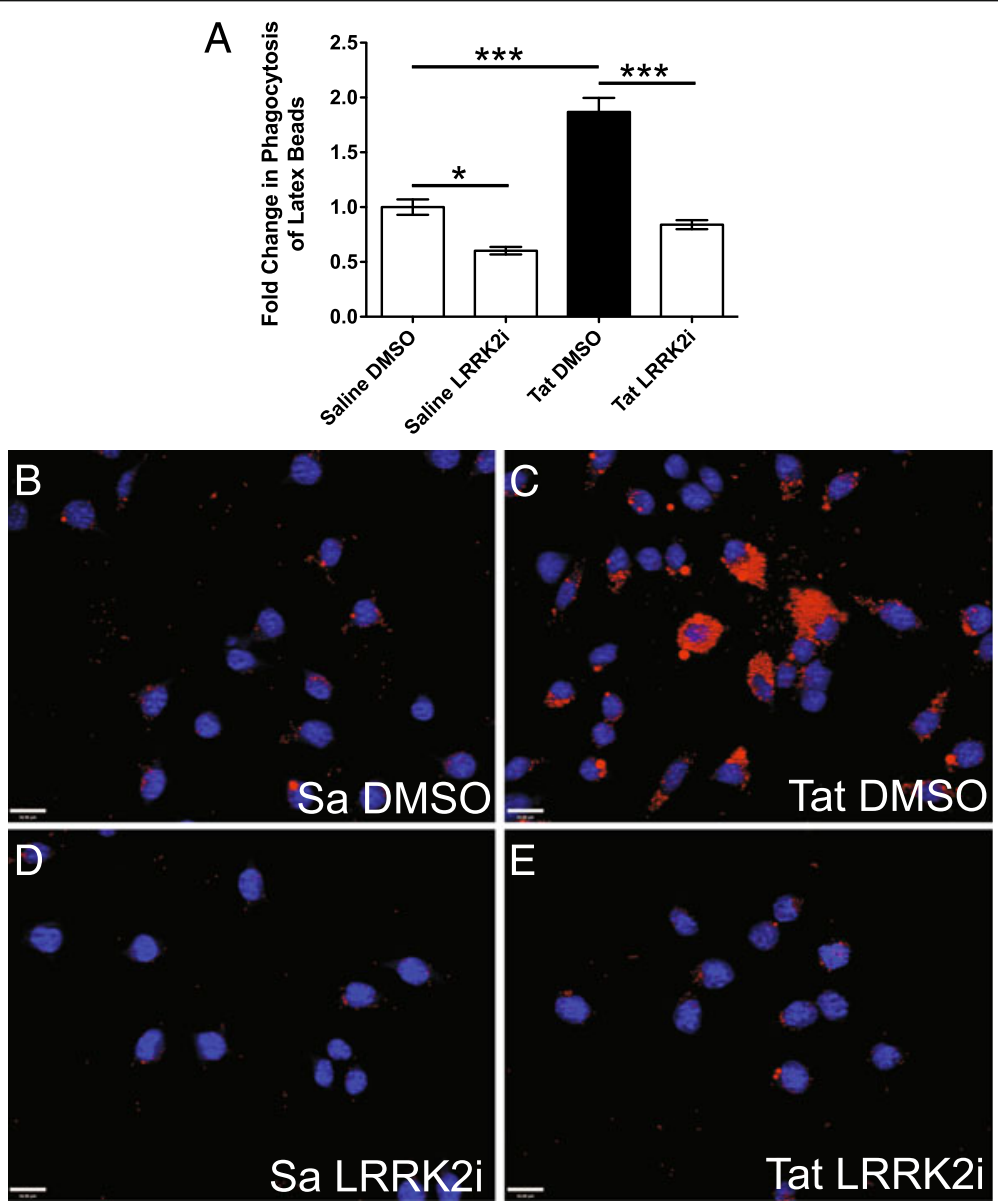

Dapi Charged Beads

Figure 3 LRRK2 kinase inhibition attenuates Tat-induced microglial phagocytosis of uncharged and carboxylated latex beads. We treated BV-2 cells with saline or Tat for 12 hours \pm LRRK2i and then exposed the cultures to uncharged latex beads for 1.5 hours. (A) LRRK2i significantly decreased Tat-induced phagocytosis of uncharged latex beads ( $n=3$ per condition). We then treated BV-2 cells with Tat for 6 hours and exposed them to carboxylated, fluorescent latex beads for 45 minutes. Cells treated with Tat (C) contain many more latex beads (red) than saline treated cells $(\mathbf{B})$. Treatment with LRRK2i in both the saline $(\mathbf{D})$ and Tat $(\mathbf{E})$ conditions decreased the number of engulfed beads ${ }^{*} P<0.05$, ${ }^{* * *} P<0.001$, one way ANOVA, Newman-Keuls post-test). ANOVA, analysis of variance; LRRK2, leucine-rich repeat kinase 2; LRRK2i, leucine-rich repeat kinase 2 inhibitor; Tat, trans activator of transcription. 
[43-45]. We found that Tat-treated BV-2 cells engulfed more beads (Figure $3 \mathrm{C}$, red signal) as compared to saline (Figure 3B) or Tat co-treatment with LRRK2i (Figure 3E). Furthermore, LRRK2i also decreased carboxylated bead engulfment in saline controls (Figure 3D), similar to results seen with uncharged beads (Figure 3A). These results indicate that treatment with LRRK2i is an effective way to reduce HIV-1 Tat-induced microglial phagocytosis, which may be partially mediated by phosphatidylserine exposure on apoptotic cell targets.

\section{Primary axonal clearance by Tat-treated microglia in microfluidic chambers is reduced by LRRK2 kinase inhibition}

As our laboratory has previously shown that microglia engulf neuronal components after exposure to HIV-1 Tat in the murine CNS [8], we used in vitro microfluidic chambers to model microglial-axonal interactions. We grew primary hippocampal neurons in microfluidic chambers that allow for physical and fluidic isolation of axons from soma. This separation allows us to study potential microglial phagocytosis of neuronal processes in the absence of neuronal cell bodies. We grew the neurons in the chambers for seven days, by which time they had developed an extensive axonal arbor (Figure 4, pre treatment). We then plated BV-2 cells in the presence of various experimental conditions in the axonal compartment, and co-cultured the cells for a further 18 hours (Figure 4, post treatment).

BV-2 cells exposed to saline $(1 \mu \mathrm{l} / \mathrm{ml})$, DMSO $(1 \mu \mathrm{l} / \mathrm{ml})$, or LRRK2i alone $(1 \mu \mathrm{M})$ did not damage the existing axonal arbor, as indicated by axon persistence (Figures 4, $5 \mathrm{~A}$ ) and growth (Figures 4, 5B). BV-2 cells exposed to Tat $(1 \mu \mathrm{g} / \mathrm{ml})$, on the other hand, completely destroyed the existing axonal arbor and prevented any further axon growth (Figures 4, 5A, 5B). The lack of remaining axonal debris indicated microglial phagocytosis of axons. We confirmed this finding using ICC, with many BV-2 cells in the Tat treated condition containing Tau 5 or Synapsin-1 positive inclusions (Figure 6C, D, E). These inclusions were not present in the saline (Figure 6A) or DMSO (Figure $6 \mathrm{~B}$ ) conditions. The addition of LRRK2i $(1 \mu \mathrm{M})$ to Tat treated BV-2 cells protected the axons from microglial clearance (Figures 4, 5B, 5A). When we examined these cells using ICC, we found the presence of some inclusions that stained positive for neuronal markers, but these

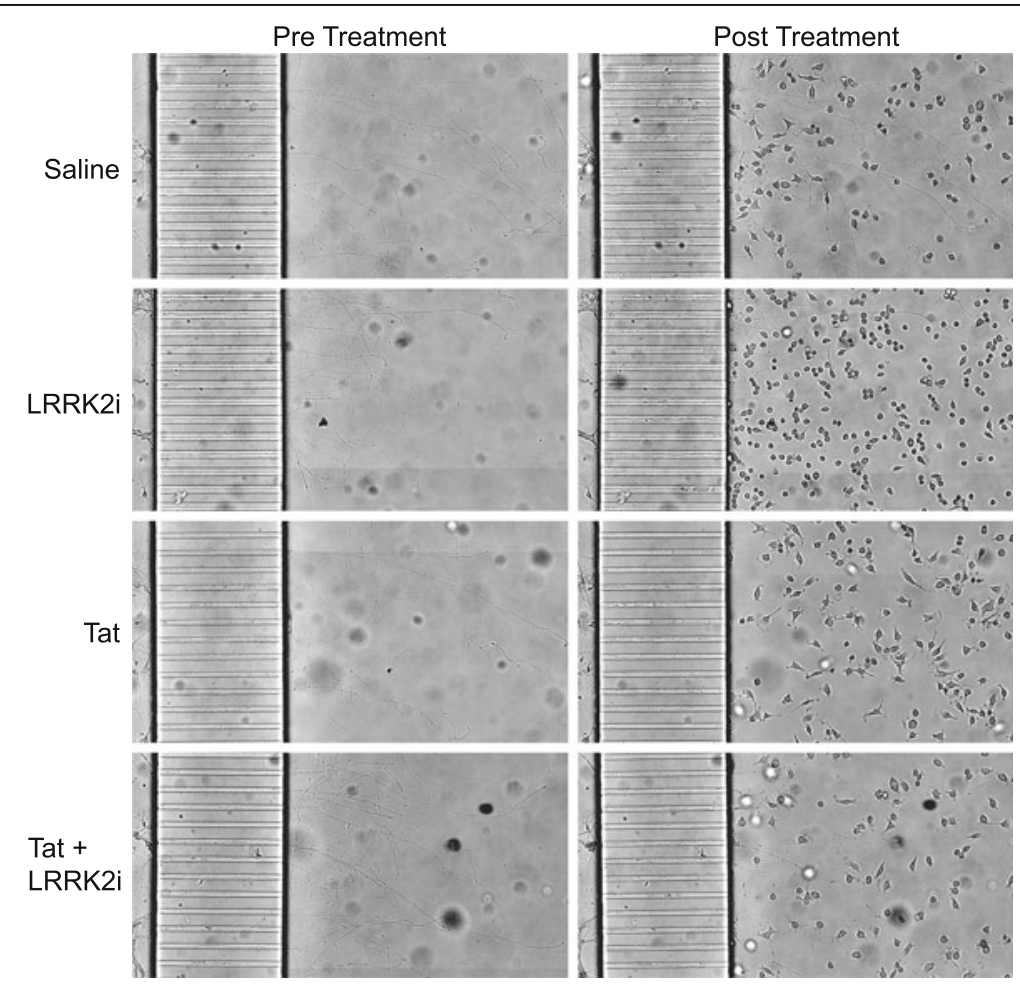

Figure 4 LRRK2 kinase inhibition protects primary axons from Tat-induced microglial phagocytosis. We co-cultured BV-2 cells along with various experimental conditions in the axonal compartment of established rat hippocampal primary neuron microfluidic chambers for 18 hours. We imaged the axonal field before and after treatment to determine the effects of the experimentally treated microglia on the neuronal structures. The figure shows representative images of axons before and after co-culture with experimentally treated BV-2 cells. Axons exposed to saline or LRRK2i treated BV-2 cells remain wholly intact, while axons exposed to Tat-treated BV-2 cells are largely destroyed. The lack of axonal debris indicates the presence of microglial phagocytosis. The addition of LRRK2i partially protects the axon field from the Tat treated BV-2 cells. LRRK2i, leucine-rich repeat kinase 2 inhibitor; Tat, trans activator of transcription. 


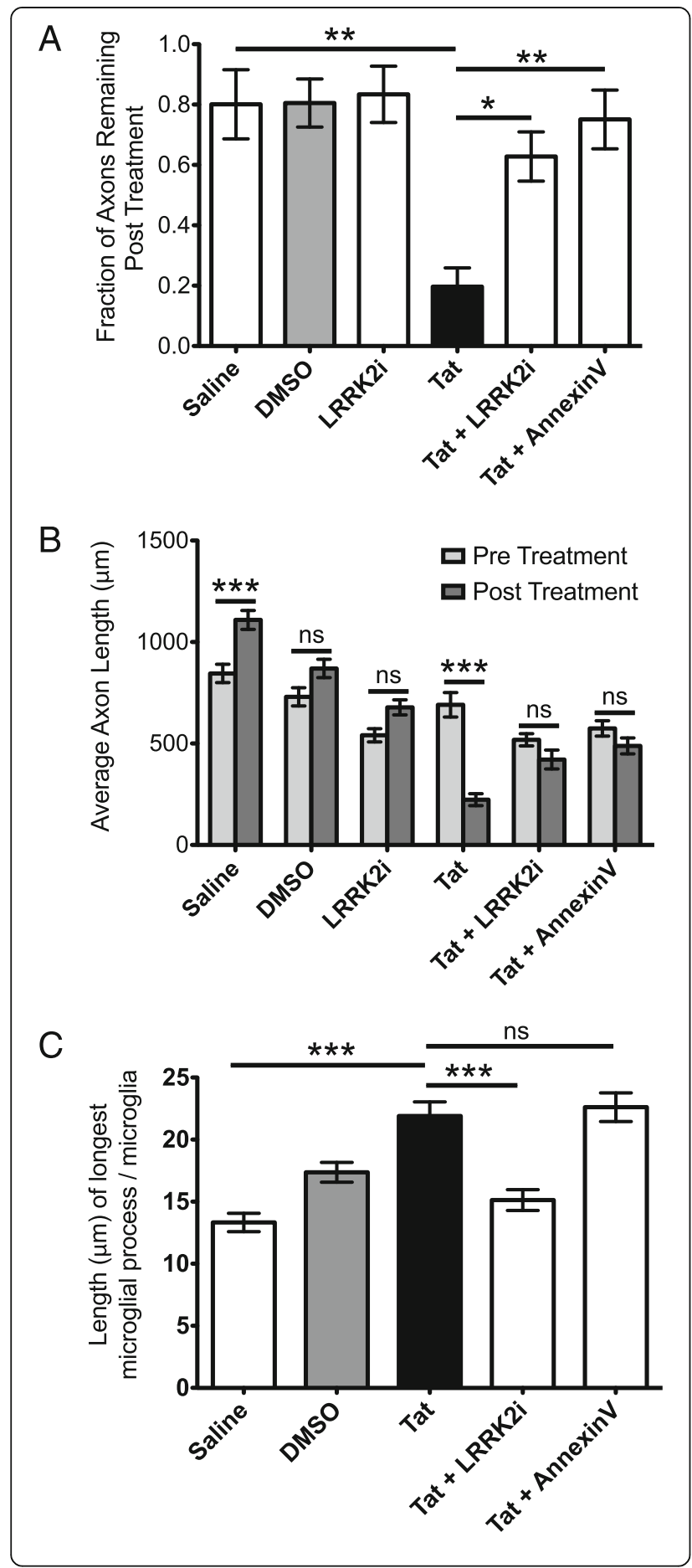

Figure 5 Quantification of the effects of LRRK2i and AnnexinV on Tat induced neuronal axon elimination, neuronal axon length, and microglia process length. (A) Approximately $80 \%$ of axons remained in microfluidic chambers after exposure to saline, DMSO, or LRRK2i alone treated BV-2 cells, where only $20 \%$ of axons remained after the addition of Tat treated BV-2 cells. The addition of LRRK2i or AnnexinV to Tat treated BV-2 cells significantly increased survival rate to $63 \%$ and $75 \%$, respectively ( $n=3$ chambers per condition, ${ }^{*} \mathrm{P}<0.05,{ }^{* * P}<0.01$, one way ANOVA, Newman-Keuls post-test). (B) Axons exposed to Tat-treated BV-2 cells are significantly shorter post treatment. Axons exposed to either DMSO, LRRK2i alone, Tat and LRRK2i, or Tat and AnnexinV treated BV-2 cells exhibited no significant change. Axons exposed to saline treated BV2 cells were significantly longer post treatment

( $n$ = a minimum of 30 axons per experimental condition,

${ }^{* * * P}<0.001$, two way ANOVA, Bonferroni post test). (C) Tat treated microglia had significantly longer processes than saline treated microglia. LRRK2 kinase inhibition normalized the microglia process length in the presence of Tat. BV-2 cells exposed to Tat and AnnexinV were not significantly different from Tat alone $\left(n=\right.$ longest process of 100 microglia in co-culture, ${ }^{*} P<0.05$, ${ }^{* * P}<0.01,{ }^{* * * P}<0.001$, one way ANOVA, Newman-Keuls post-test). ANOVA, analysis of variance; DMSO dimethyl sulfoxide; LRRK2i, leucine-rich repeat kinase 2 inhibitor; Tat, trans activator of transcription.

inclusions were much smaller and morphologically different from those in the Tat treatment alone (Figure 6F).

Tat-induced axonal phagocytosis is partially dependent on phosphatidylserine exposure to BV-2 cells

To determine if microglial phagocytosis of axons was phosphatidylserine dependent, we co-treated BV-2s with Tat and AnnexinV. AnnexinV $(1 \mu \mathrm{g} / \mathrm{ml})$ protected the axonal field from the Tat treated BV-2 cells (Figures 5A, 5B, 7A-B). BV-2 cells treated with both Tat and AnnexinV did contain neuronal marker positive inclusions similar to those in the Tat only condition (Figure 6G), but at a far smaller rate than Tat alone (data not shown). In order to investigate how LRRK2i may inhibit phagocytosis based on this result, we measured the expression of two phosphatidylserine receptors, BAI1 and TIM4, in BV-2 cells. We did not find any TIM4 expression in BV-2 cells (data not shown). BAI1 expression increased after Tat treatment, although not significantly (Figure 7C). LRRK2i significantly decreased BAI1 expression to control levels in Tattreated BV-2 cells (Figure 7C). Taken together, these results indicate a role for phosphatidylserine receptor mediated phagocytosis of neuronal components.

\section{Microglia morphology is altered by Tat treatment and LRRK2i during microfluidic coculture with primary neuronal axons}

Finally, we analyzed the morphology of the experimentally treated microglia in the presence of axons. We 

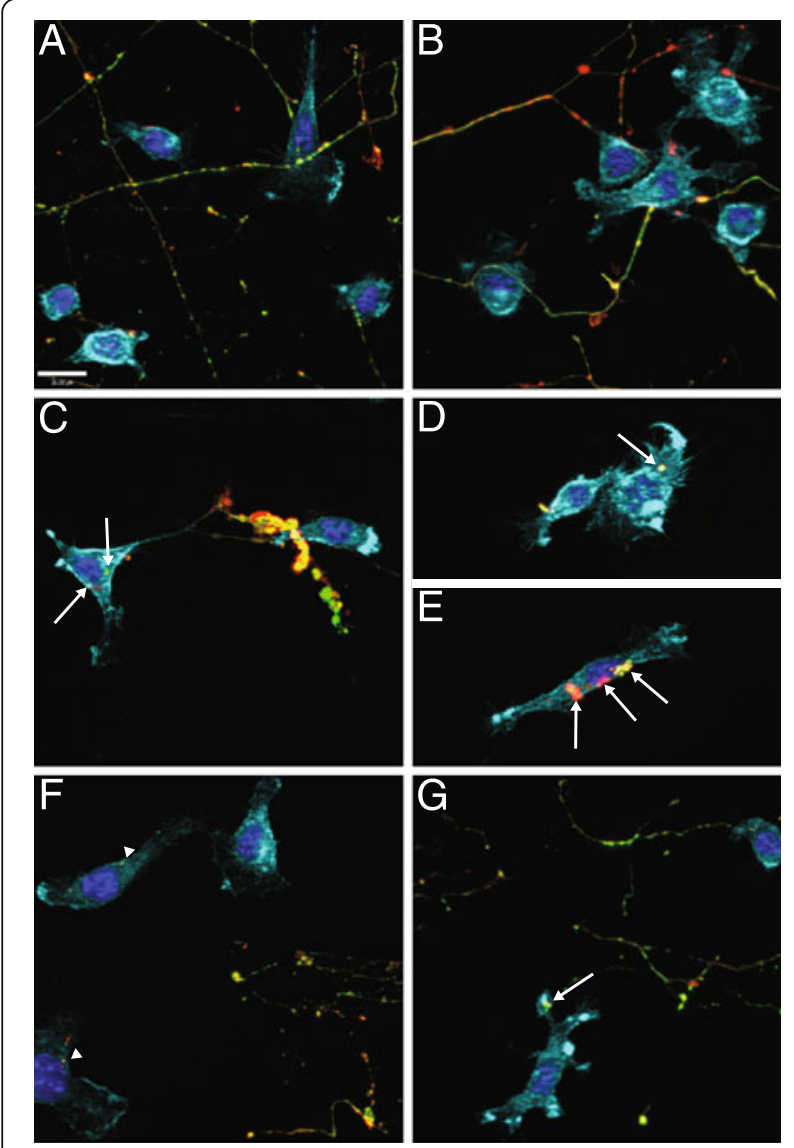

CD11b

Figure 6 Tat-treated BV-2 cells cultured with primary axons contain inclusions of neuronal components that are altered by LRRK2 kinase inhibition. We immunostained BV-2-neuronal

cultures for the axonal cytoskeletal protein Tau 5 (green), the axonal terminal protein Synapsin-1 (red), and the microglial membrane protein CD11b (light blue) after 18 hours of experimental treatment. Saline (A) and DMSO (B) treated BV-2 cells do not appear to phagocytose any neuronal components. Tat treated BV-2 cells

(C, D, E) contain Tau-5 and Synapsin-1 positive inclusions, indicative of axonal phagocytosis (white arrows). Tat exposed BV-2 cells treated with LRRK2i (F) contain some neuronal inclusions that are much smaller than Tat exposed alone (white arrowheads), indicating a stunted phagocytic process. Tat exposed BV-2 cells treated with AnnexinV (G) contain fewer inclusions than Tat alone, but the inclusions are the same size as the Tat alone treated condition (white arrows). LRRK2i, leucine-rich repeat kinase 2 inhibitor; Tat, trans activator of transcription.

found that Tat exposed microglia extended processes longer than controls, and that this process is inhibited with the addition of LRRK2i, similar to our findings in monocultures of BV-2 cells (Figure 5C). Surprisingly, the addition of AnnexinV did not inhibit microglia process extension (Figure $5 \mathrm{C}$ ), indicating that the microglia are still activated despite the absence of neuronal phagocytosis in this condition.

\section{Discussion}

LRRK2 is a large signal transduction protein with a MAPKKK domain. Mutations in LRRK2 are strongly linked to Parkinson's disease (PD) [9]. The principal finding from our data supports the hypothesis that LRRK2 regulates microglial activation after exposure to HIV-1 Tat, affecting both microglial pro-inflammatory cytokine expression and phagocytosis. This functional change in microglia may account for synaptic damage,

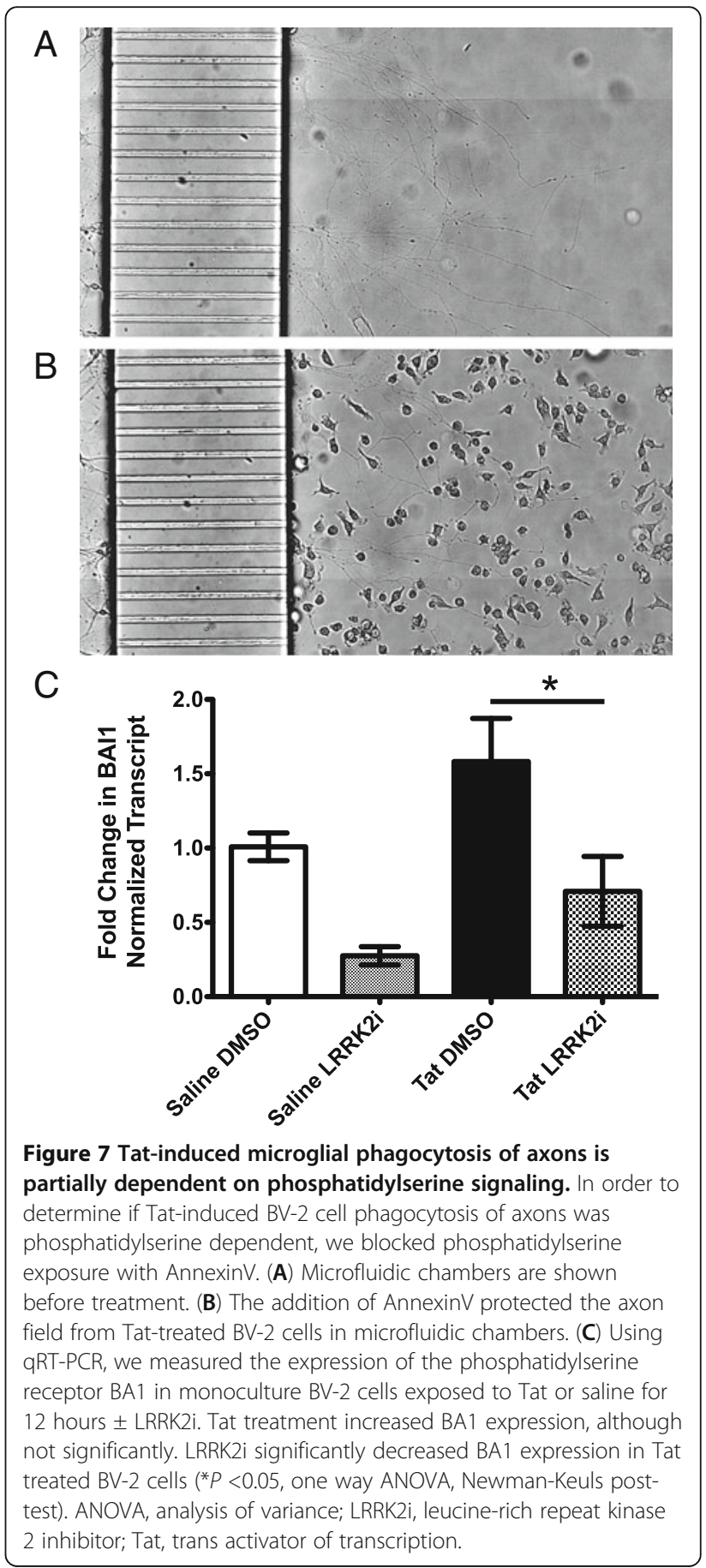


which is a cornerstone of the neuropathology observed in HANDs [46].

While it is known that Tat induces the release of the pro-inflammatory cytokine TNF-alpha in microglia, how Tat alters phagocytosis in microglia is not well understood [47]. Several recent publications from the Brown group show that preventing microglia phagocytosis is sufficient to protect neurons exposed to either LPS or micromolar levels of amyloid beta (A $\beta$ ) [48-51]. These results indicate a primary role of microglial phagocytosis in certain neurodegenerative and neuroinflammatory conditions. Our in vitro microfluidic co-culture system mimics these findings in the context of HANDs. A recent publication indicated that treatment with Tat decreased phagocytosis of $A \beta$ peptide in primary microglia [52], indicating that microglial phagocytosis may be substratespecific during neuroinflammation. These data add an additional dimension of complexity to microglial mechanisms of neuroinflammation when multiple disorders occur simultaneously within the CNS and highlight the importance of understanding microglial phagocytosis during neurodegeneration.

Several recent studies investigating LRRK2 in LPSinduced microglial activation have shown that LRRK2 knockout and the LRRK2(R1441G) mutation attenuated and augmented microglial inflammation, respectively $[18,21,30]$. Interestingly, phosphorylation of LRRK2 at S910 and S935 occurs during Toll-like receptor signaling in bone marrow derived macrophages [53]. Our results extend these findings to show that Tat treatment also induces phosphorylation at S935 of LRRK2, suggesting additional loci for Tat to perturb LRRK2 function in infiltrating pro-inflammatory macrophages in the CNS.

Furthermore, LRRK2 has been found to form inclusions when in the presence of LRRK2i in HEK-293 cells [12], lymphoblastoid cells [11], and rat brain [54]. We did not observe LRRK2 inclusions in the presence of LRRK2i in BV-2 cells, which may indicate that this phenomenon is cell-type specific. However, we did observe LRRK2 aggregation after Tat treatment in BV-2 cells, in the form of several $1 \mu \mathrm{m}$ LRRK2-positive vesicles. Recent publications have linked LRRK2 to the autophagy pathway in macrophages [16], kidney [28] and brain [55-57]. Future studies from our laboratory will focus on the purpose of these inclusions and whether they represent an altered role for LRRK2 and the autophagy pathway within these cells.

There is a distinct possibility that some of the axonal protection we observe with the use of the LRRK2i is provided by LRRK2 kinase inhibition in the axons themselves, and not from the anti-inflammatory effects in the microglia alone. LRRK2 kinase over-activity, specifically due to the LRRK2(G2019S) mutation, has been shown to decrease neurite outgrowth and complexity, in both in vitro and in vivo models [26,56-59]. It is, therefore, possible that LRRK2 kinase inhibition may impart some protection to established axons, but the effect of LRRK2 kinase over-activity or inhibition in established axons in our paradigms has not yet been directly studied.

Our studies did not attempt to establish a mechanism for how LRRK2 inhibition may prevent microglia phagocytosis. However, the ability of AnnexinV to block axonal phagocytosis and the decrease in BAI1 expression in Tat-treated BV-2 cells after LRRK2i treatment indicates that Tat-induced phagocytosis is, at least in part, phosphatidylserine-dependent. Additionally, while the role of LRRK2 in effecting the neuronal cytoskeleton has been well established [58], a recent publication has implicated LRRK2 more generally in actin cytoskeletal dynamics [60]. Actin reorganization is critical in microglial phagocytosis, providing a potential mechanism for the reduced phagocytosis in the LRRK2i treated BV-2 cells [61]. Furthermore, LRRK2 knockdown has been found to reduce reactive oxygen species production during bacterial engulfment in macrophages [20].

These findings provide the basis for future studies, not only in relation to LRRK2 and phagocytosis, but also to better understand the mechanisms of neuronal phagocytosis by microglia. These phenomena have been implicated in several neurodegenerative and neuroinflammatory diseases, such as PD, Alzheimer's disease and HANDs [8,50,51]. This work may lead to novel LRRK2-based therapeutic strategies to inhibit microglial inflammation and phagocytosis of the neuronal arbor.

\section{Conclusions}

LRRK2i limits inflammatory cytokine expression and phagocytosis of neuronal components by microglia exposed to HIV-1 Tat. These results implicate LRRK2i as a potential means for developing an adjunctive therapy for HANDs, as well as other neuroinflammatory disorders where LRRK2 may be contributing to pathology.

\section{Abbreviations \\ $A \beta$ : Amyloid $\beta$; BSA: Bovine serum albumin; CART: Combination antiretroviral therapy; CNS: Central nervous system; (D)MEM: (Dulbecco's) modified Eagle's serum; ECL: Enhanced chemiluminescence; FBS: Fetal bovine serum; HANDS: HIV-1 associated neurocognitive disorders; \\ ICC: Immumocytochemistry; IL: Interleukin; LPS: Lipopolysaccharide; LRRK2: Leucine-rich repeat kinase 2; LRRK2i: Leucine-rich repeat kinase 2 inhibitor; MAPKKK: Mitogen-activated protein kinase kinase kinase; NF-kß: Nuclear factor-kappa beta; PBS: Phosphate-buffered serum; PD: Parkinson's disease; pS935: Phosphorylation of serine 935; PVDF: Polyvinylidene difluoride; qRT-PCR: Quantitative reverse transcriptase-polymerase chain reaction; Tat: Trans activator of transcription; TNF-a: Tumor necrosis factor a.}

\section{Competing interests}

The authors declare that they have no competing interests.

\section{Authors' contributions}

DFM carried out microfluidic chamber experiments and immunocytochemistry. JMP, TEM and JB carried out GRT-PCR and phagocytosis assay experiments. JMP carried out western blots and 
immunocytochemistry. DFM, JMP, SML, and HAG participated in data analysis and writing of the manuscript. All authors read and approved the final manuscript.

\section{Acknowledgements}

The authors wish to thank Angela Stout for neuronal cell isolation and Marc Halterman for use of his real time PCR machine. This study was supported by PO1 MH64570 and RO1 MH56838 (HAG); T32 GM007356, T32 Al49815, F30 MH095664 (DFM); F32MH099913 (JMP); P30Al078498 D-CFAR

Received: 7 September 2012 Accepted: 9 November 2012 Published: 29 November 2012

\section{References}

1. Heaton RK, Clifford DB, Franklin DR Jr, Woods SP, Ake C, Vaida F, Ellis RJ, Letendre SL, Marcotte TD, Atkinson JH, Rivera-Mindt M, Vigil OR, Taylor MJ, Collier AC, Marra CM, Gelman BB, McArthur JC, Morgello S, Simpson DM, McCutchan JA, Abramson I, Gamst A, Fennema-Notestine C, Jernigan TL, Wong J, Grant I, CHARTER Group: HIV-associated neurocognitive disorders persist in the era of potent antiretroviral therapy: CHARTER Study. Neurology 2010, 75:2087-2096.

2. Anderson E, Zink W, Xiong H, Gendelman HE: HIV-1-associated dementia: a metabolic encephalopathy perpetrated by virus-infected and immunecompetent mononuclear phagocytes. J Acquir Immune Defic Syndr 2002, 31(Suppl 2):S43-S54

3. Kure K, Lyman WD, Weidenheim KM, Dickson DW: Cellular localization of an HIV-1 antigen in subacute AIDS encephalitis using an improved double-labeling immunohistochemical method. Am J Pathol 1990, 136:1085-1092.

4. Mothobi NZ, Brew BJ: Neurocognitive dysfunction in the highly active antiretroviral therapy era. Curr Opin Infect Dis 2012, 25:4-9.

5. Cowley D, Gray LR, Wesselingh SL, Gorry PR, Churchill MJ: Genetic and functional heterogeneity of CNS-derived tat alleles from patients with HIV-associated dementia. J Neurovirol 2011, 17:70-81.

6. Li W, Li G, Steiner J, Nath A: Role of Tat protein in HIV neuropathogenesis. Neurotox Res 2009, 16:205-220.

7. Sui Z, Fan S, Sniderhan L, Reisinger E, Litzburg A, Schifitto G, Gelbard HA, Dewhurst S, Maggirwar SB: Inhibition of mixed lineage kinase 3 prevents HIV-1 Tat-mediated neurotoxicity and monocyte activation. J Immunol 2006, 177:702-711.

8. Lu SM, Tremblay ME, King IL, Qi J, Reynolds HM, Marker DF, Varrone Jر, Majewska AK, Dewhurst S, Gelbard HA: HIV-1 Tat-induced microgliosis and synaptic damage via interactions between peripheral and central myeloid cells. PLoS One 2011, 6:e23915.

9. Seol W: Biochemical and molecular features of LRRK2 and its pathophysiological roles in Parkinson's disease. BMB Rep 2010 43:233-244.

10. Gloeckner CJ, Boldt K, von Zweydorf F, Helm S, Wiesent L, Sarioglu H, Ueffing M: Phosphopeptide analysis reveals two discrete clusters of phosphorylation in the N-terminus and the Roc domain of the Parkinson-disease associated protein kinase LRRK2. J Proteome Res 2010, 9:1738-1745.

11. Dzamko N, Deak M, Hentati F, Reith AD, Prescott AR, Alessi DR, Nichols RJ: Inhibition of LRRK2 kinase activity leads to dephosphorylation of Ser (910)/Ser(935), disruption of 14-3-3 binding and altered cytoplasmic localization. Biochem J 2010, 430:405-413.

12. Deng X, Dzamko N, Prescott A, Davies P, Liu Q, Yang Q, Lee JD, Patricelli MP, Nomanbhoy TK, Alessi DR, Gray NS: Characterization of a selective inhibitor of the Parkinson's disease kinase LRRK2. Nat Chem Biol 2011 7:203-205.

13. Barrett JC, Hansoul S, Nicolae DL, Cho JH, Duerr RH, Rioux JD, Brant SR, Silverberg MS, Taylor KD, Barmada MM, Bitton A, Dassopoulos T, Datta LW, Green T, Griffiths AM, Kistner EO, Murtha MT, Regueiro MD, Rotter Jl, Schumm LP, Steinhart AH, Targan SR, Xavier RJ, Libioulle C, Sandor C, Lathrop M, Belaiche J, Dewit O, Gut I, Heath S, et al: Genome-wide association defines more than 30 distinct susceptibility loci for Crohn's disease. Nat Genet 2008, 40:955-962.

14. Zhang FR, Huang W, Chen SM, Sun LD, Liu H, Li Y, Cui Y, Yan XX, Yang HT, Yang RD, Chu TS, Zhang C, Zhang L, Han JW, Yu GQ, Quan C, Yu YX, Zhang Z, Shi BQ, Zhang LH, Cheng H, Wang CY, Lin Y, Zheng HF, Fu XA, Zuo XB,
Wang Q, Long H, Sun YP, Cheng YL, et al: Genomewide association study of leprosy. N Eng J Med 2009, 361:2609-2618.

15. Zimprich A, Biskup S, Leitner $P$, Lichtner $P$, Farrer $M$, Lincoln $S$, Kachergus J, Hulihan M, Uitti RJ, Calne DB, Stoessl AJ, Pfeiffer RF, Patenge N, Carbajal IC, Vieregge P, Asmus F, Müller-Myhsok B, Dickson DW, Meitinger T, Strom TM Wszolek ZK, Gasser T: Mutations in LRRK2 cause autosomal-dominant parkinsonism with pleomorphic pathology. Neuron 2004, 44:601-607.

16. Hakimi M, Selvanantham T, Swinton E, Padmore RF, Tong Y, Kabbach G, Venderova K, Girardin SE, Bulman DE, Scherzer CR, LaVoie MJ, Gris D, Park DS, Angel JB, Shen J, Philpott DJ, Schlossmacher MG: Parkinson's diseaselinked LRRK2 is expressed in circulating and tissue immune cells and upregulated following recognition of microbial structures. J Neural Transm 2011, 118:795-808.

17. Liu Z, Lee J, Krummey S, Lu W, Cai H, Lenardo MJ: The kinase LRRK2 is a regulator of the transcription factor NFAT that modulates the severity of inflammatory bowel disease. Nat Immuno/ 2011, 12:1063-1070.

18. Moehle MS, Webber PJ, Tse T, Sukar N, Standaert DG, DeSilva TM, Cowell RM, West AB: LRRK2 inhibition attenuates microglial inflammatory responses. J Neurosci 2012, 32:1602-1611.

19. Tufekci KU, Meuwissen R, Genc S, Genc K: Inflammation in Parkinson's disease. Adv Protein Chem Struct Biol 2012, 88:69-132.

20. Gardet A, Benita Y, Li C, Sands BE, Ballester I, Stevens C, Korzenik JR, Rioux JD, Daly MJ, Xavier RJ, Podolsky DK: LRRK2 is involved in the IFN-gamma response and host response to pathogens. J Immunol 2010 185:5577-5585.

21. Kim B, Yang MS, Choi D, Kim JH, Kim HS, Seol W, Choi S, Jou I, Kim EY, Joe EH: Impaired inflammatory responses in murine Irrk2-knockdown brain microglia. PLoS One 2012, 7:e34693.

22. Greggio E, Civiero L, Bisaglia M, Bubacco L: Parkinson's disease and immune system: is the culprit LRRKing in the periphery? J Neuroinflammation 2012, 9:94.

23. Gandhi PN, Chen SG, Wilson-Delfosse AL: Leucine-rich repeat kinase 2 (LRRK2): a key player in the pathogenesis of Parkinson's disease. J Neurosci Res 2009, 87:1283-1295.

24. Rudenko IN, Chia R, Cookson MR: Is inhibition of kinase activity the only therapeutic strategy for LRRK2-associated Parkinson's disease? BMC Med 2012, 10:20.

25. Chen CY, Weng YH, Chien KY, Lin KJ, Yeh TH, Cheng YP, Lu CS, Wang HL: (G2019S) LRRK2 activates MKK4-JNK pathway and causes degeneration of SN dopaminergic neurons in a transgenic mouse model of PD. Cell Death Differ 2012, 19:1623-1633.

26. Winner B, Melrose HL, Zhao C, Hinkle KM, Yue M, Kent C, Braithwaite AT, Ogholikhan S, Aigner R, Winkler J, Farrer MJ, Gage FH: Adult neurogenesis and neurite outgrowth are impaired in LRRK2 G2019S mice. Neurobiol Dis 2011, 41:706-716.

27. Melrose H, Lincoln S, Tyndall G, Dickson D, Farrer M: Anatomical localization of leucine-rich repeat kinase 2 in mouse brain. Neuroscience 2006, 139:791-794.

28. Tong Y, Yamaguchi H, Giaime E, Boyle S, Kopan R, Kelleher RJ 3rd, Shen J: Loss of leucine-rich repeat kinase 2 causes impairment of protein degradation pathways, accumulation of alpha-synuclein, and apoptotic cell death in aged mice. Proc Natl Acad Sci U S A 2010, 107:9879-9884.

29. Kim WG, Mohney RP, Wilson B, Jeohn GH, Liu B, Hong JS: Regional difference in susceptibility to lipopolysaccharide-induced neurotoxicity in the rat brain: role of microglia. J Neurosci 2000, 20:6309-6316.

30. Gillardon F, Schmid R, Draheim H: Parkinson's disease-linked leucine-rich repeat kinase $2(\mathrm{R} 1441 \mathrm{G})$ mutation increases proinflammatory cytokine release from activated primary microglial cells and resultant neurotoxicity. Neuroscience 2012, 208:41-48.

31. Chan D, Citro A, Cordy JM, Shen GC, Wolozin B: Rac1 protein rescues neurite retraction caused by G2019S leucine-rich repeat kinase 2 (LRRK2). J Biol Chem 2011, 286:16140-16149.

32. Kim HJ, Martemyanov KA, Thayer SA: Human immunodeficiency virus protein Tat induces synapse loss via a reversible process that is distinct from cell death. J Neurosci 2008, 28:12604-12613.

33. Glynn MW, McAllister AK: Immunocytochemistry and quantification of protein colocalization in cultured neurons. Nat Protoc 2006, 1:1287-1296.

34. Park JW, Vahidi B, Taylor AM, Rhee SW, Jeon NL: Microfluidic culture platform for neuroscience research. Nat Protoc 2006, 1:2128-2136.

35. Edelstein A, Amodaj N, Hoover K, Vale R, Stuurman N: Computer control of microscopes using microManager. In Current Protocols in Molecular Biology, 
Chapter 14:Unit14 20. Edited by Ausubel FM, et al. Hoboken, NJ: Wiley-Blackwell; 2010.

36. Schneider CA, Rasband WS, Eliceiri KW: NIH Image to ImageJ: 25 years of image analysis. Nat Methods 2012, 9:671-675.

37. Meijering E, Jacob M, Sarria JC, Steiner P, Hirling H, Unser M: Design and validation of a tool for neurite tracing and analysis in fluorescence microscopy images. Cytometry A 2004, 58:167-176.

38. Bocchini V, Mazzolla R, Barluzzi R, Blasi E, Sick P, Kettenmann H: An immortalized cell line expresses properties of activated microglial cells. J Neurosci Res 1992, 31:616-621.

39. Tyor WR, Glass JD, Griffin JW, Becker PS, McArthur JC, Bezman L, Griffin DE: Cytokine expression in the brain during the acquired immunodeficiency syndrome. Ann Neurol 1992, 31:349-360.

40. Xing HQ, Hayakawa H, Izumo K, Kubota R, Gelpi E, Budka H, Izumo S: In vivo expression of proinflammatory cytokines in HIV encephalitis: an analysis of 11 autopsy cases. Neuropathology 2009, 29:433-442.

41. El-Hage N, Wu G, Wang J, Ambati J, Knapp PE, Reed JL, Bruce-Keller AJ, Hauser KF: HIV-1 Tat and opiate-induced changes in astrocytes promote chemotaxis of microglia through the expression of MCP-1 and alternative chemokines. Glia 2006, 53:132-146.

42. Eugenin EA, Osiecki K, Lopez L, Goldstein H, Calderon TM, Berman JW: CCL2/monocyte chemoattractant protein-1 mediates enhanced transmigration of human immunodeficiency virus (HIV)-infected leukocytes across the blood-brain barrier: a potential mechanism of HIV-CNS invasion and NeuroAIDS. J Neurosci 2006, 26:1098-1106.

43. Wu Y, Tibrewal N, Birge RB: Phosphatidylserine recognition by phagocytes: a view to a kill. Trends Cell Biol 2006, 16:189-197.

44. Kiss RS, Elliott MR, Ma Z, Marcel YL, Ravichandran KS: Apoptotic cells induce a phosphatidylserine-dependent homeostatic response from phagocytes. Curr Biol 2006, 16:2252-2258.

45. Park D, Tosello-Trampont AC, Elliott MR, Lu M, Haney LB, Ma Z, Klibanov AL, Mandell JW, Ravichandran KS: BAI1 is an engulfment receptor for apoptotic cells upstream of the ELMO/Dock180/Rac module. Nature 2007, 450:430-434.

46. Masliah E, Heaton RK, Marcotte TD, Ellis RJ, Wiley CA, Mallory M, Achim CL, McCutchan JA, Nelson JA, Atkinson JH, Grant I: Dendritic injury is a pathological substrate for human immunodeficiency virus-related cognitive disorders. HNRC Group. The HIV Neurobehavioral Research Center. Ann Neurol 1997, 42:963-972.

47. Buscemi L, Ramonet D, Geiger JD: Human immunodeficiency virus type-1 protein Tat induces tumor necrosis factor-alpha-mediated neurotoxicity. Neurobiol Dis 2007, 26:661-670.

48. Brown GC, Neher JJ: Eaten alive! Cell death by primary phagocytosis: 'phagoptosis'. Trends Biochem Sci 2012, 37:325-332.

49. Neher JJ, Neniskyte U, Brown GC: Primary phagocytosis of neurons by inflamed microglia: potential roles in neurodegeneration. Front Pharmacol 2012, 3:27.

50. Neher JJ, Neniskyte U, Zhao JW, Bal-Price A, Tolkovsky AM, Brown GC: Inhibition of microglial phagocytosis is sufficient to prevent inflammatory neuronal death. J Immuno/ 2011, 186:4973-4983.

51. Neniskyte U, Neher JJ, Brown GC: Neuronal death induced by nanomolar amyloid beta is mediated by primary phagocytosis of neurons by microglia. J Biol Chem 2011, 286:39904-39913.

52. Giunta B, Zhou Y, Hou H, Rrapo E, Fernandez F, Tan J: HIV-1 TAT inhibits microglial phagocytosis of Abeta peptide. Int J Clin Exp Pathol 2008, 1:260-275.

53. Dzamko N, Inesta-Vaquera F, Zhang J, Xie C, Cai H, Arthur S, Tan L, Choi H, Gray N, Cohen P, Pedrioli P, Clark K, Alessi DR: The IkappaB Kinase family phosphorylates the Parkinson's disease Kinase LRRK2 at Ser935 and Ser910 during toll-like receptor signaling. PLoS One 2012, 7:e39132.

54. Biskup S, Moore DJ, Celsi F, Higashi S, West AB, Andrabi SA, Kurkinen K, Yu SW, Savitt JM, Waldvogel HJ, Faull RL, Emson PC, Torp R, Ottersen OP, Dawson TM, Dawson VL: Localization of LRRK2 to membranous and vesicular structures in mammalian brain. Ann Neurol 2006, 60:557-569.

55. Friedman LG, Lachenmayer ML, Wang J, He L, Poulose SM, Komatsu M, Holstein GR, Yue Z: Disrupted autophagy leads to dopaminergic axon and dendrite degeneration and promotes presynaptic accumulation of alpha-synuclein and LRRK2 in the Brain. J Neurosci 2012, 32:7585-7593.
56. Plowey ED, Cherra SJ 3rd, Liu YJ, Chu CT: Role of autophagy in G2019S-LRRK2-associated neurite shortening in differentiated SH-SY5Y cells. J Neurochem 2008, 105:1048-1056.

57. Ramonet D, Daher JP, Lin BM, Stafa K, Kim J, Banerjee R, Westerlund M Pletnikova O, Glauser L, Yang L, Liu Y, Swing DA, Beal MF, Troncoso JC, McCaffery JM, Jenkins NA, Copeland NG, Galter D, Thomas B, Lee MK, Dawson TM, Dawson VL, Moore DJ: Dopaminergic neuronal loss, reduced neurite complexity and autophagic abnormalities in transgenic mice expressing G2019S mutant LRRK2. PLoS One 2011, 6:e18568.

58. Kawakami F, Yabata T, Ohta E, Maekawa T, Shimada N, Suzuki M, Maruyama $H$, Ichikawa T, Obata F: LRRK2 phosphorylates tubulin-associated tau but not the free molecule: LRRK2-mediated regulation of the tau-tubulin association and neurite outgrowth. PLoS One 2012, 7:e30834.

59. MacLeod D, Dowman J, Hammond R, Leete T, Inoue K, Abeliovich A: The familial Parkinsonism gene LRRK2 regulates neurite process morphology. Neuron 2006, 52:587-593.

60. Meixner A, Boldt K, Van Troys M, Askenazi M, Gloeckner CJ, Bauer M, Marto JA, Ampe C, Kinkl N, Ueffing M: A QUICK screen for Lrrk2 interaction partners-leucine-rich repeat kinase 2 is involved in actin cytoskeleton dynamics. Mol Cell Proteomics 2011, 10:M110 001172.

61. Abd-el-Basset EM, Fedoroff S: Dynamics of actin filaments in microglia during Fc receptor-mediated phagocytosis. Acta Neuropathol 1994, 88:527-537.

doi:10.1186/1742-2094-9-261

Cite this article as: Marker et al.: LRRK2 kinase inhibition prevents pathological microglial phagocytosis in response to HIV-1 Tat protein. Journal of Neuroinflammation 9:261.

\section{Submit your next manuscript to BioMed Central and take full advantage of:}

- Convenient online submission

- Thorough peer review

- No space constraints or color figure charges

- Immediate publication on acceptance

- Inclusion in PubMed, CAS, Scopus and Google Scholar

- Research which is freely available for redistribution

Submit your manuscript at www.biomedcentral.com/submit
C Biomed Central 